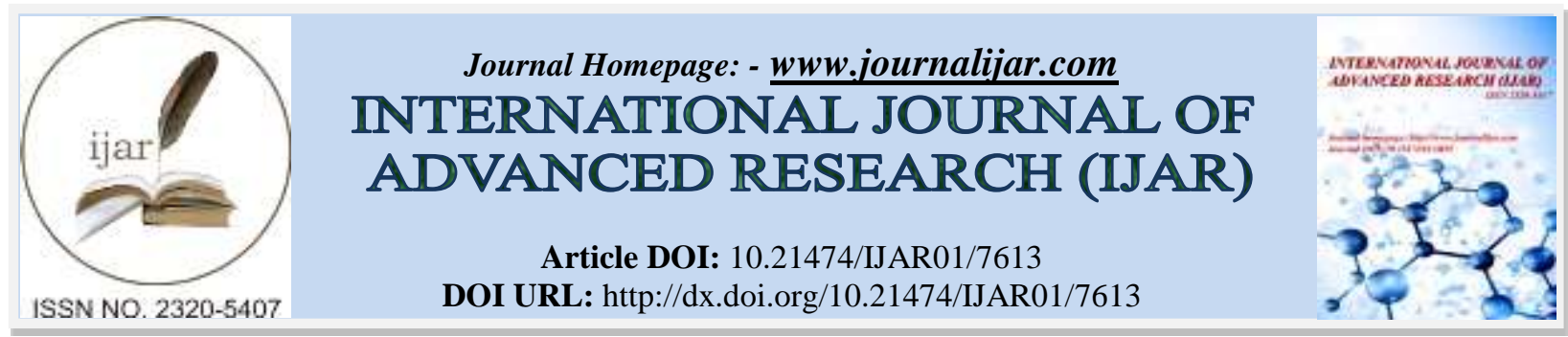

RESEARCH ARTICLE

\title{
EPIDEMIOLOGY AND ENVIRONMENTAL DETERMINANTS OF BRONCHIAL ASTHMA AMONG CHILDREN IN AL-MADINA, SAUDI ARABIA.
}

Tahani M O Alharbi, Rawan A A Abu alola and Magda H M Youssef.

\section{Manuscript Info}

\section{Manuscript History}

Received: 22 June 2018

Final Accepted: 24 July 2018

Published: August 2018

\section{Keywords:-}

bronchial asthma; environmental; dietary; BMI, Al-Madina, Saudi Arabia.
Abstract

Background: Bronchial asthma is a chronic respiratory disease characterized by the inflammation of the airways of the lungs. Worldwide, people are affected by it without distinction for ethnicity, age or gender. Its exacerbation and complications can be prevented by maintaining good control over the condition.

Objective: The objective of this study was to identify the prevalence rate of bronchial asthma among children in the city of Al-Madina, Saudi Arabia. This will also facilitate the study of possible environmental and dietary determinants of bronchial asthma among asthmatic children (1-14 years old) and in evaluating the severity of asthma and its effects on the quality of life.

Methods: A cross-sectional study was performed from March to May 2018 with a representative sample of Saudi male and female children at the Maternity and Children's Hospital, Al-Madina, Saudi Arabia (N= 339). The age of the children was $\leq 14$ years old. A self-administered questionnaire was distributed and was filled in by parents who satisfied the selection criteria of the study.

Results: In the study, $56.8 \%$ of the sample were male children. $48.2 \%$ of the parents reported that their children have asthma. The body mass index (BMI) of the children between the ages ( $>2$ years to $\leq 14$ years) showed that $83.2 \%$ of them were underweight. $35.9 \%$ of the total sample took medication for asthma. Passive smoking was the most common environmental risk factor, encountered by $25.78 \%$ of the total sample. Egg consumption was the most common dietary risk factor, connected with $11.98 \%$ of the total sample. As regards the severity of bronchial asthma, $71.9 \%$ of children had not been absent from their schools in this year, and the majority of asthmatic participants did not need to visit the hospital.

Conclusion: This study identifies that the prevalence of bronchial asthma among children in Al-Madina was $48.2 \%$ of the total sample. Passive smoking was the most widespread environmental risk factor that could trigger asthma symptoms. Moreover, egg consumption was the most common dietary risk factors associated with asthmatic children. 


\section{Introduction:-}

Asthma is a significant health problem worldwide; 300 million individuals are affected, and it results in 250,000 annual deaths (1). Bronchial asthma is a chronic airway disorder with recurrent attacks of wheezing, coughing, chest tightness and breathlessness, especially at night or in the early morning. It is marked by cellular inflammation and mucosal oedema, leading to airway narrowing that may be improved with or without treatment. It can be a lifethreatening condition that needs to immediate medical intervention.

In the Kingdom of Saudi Arabia, asthma is considered one of the most prevalent chronic illnesses, affecting about 2 million people (2). Despite the availability of many adequate health services and the presence of worldwide guidelines, several studies have shown that the prevalence of asthma is increasing, particularly among children and adolescents. A cross-sectional study among school children in multiple regions of the Kingdom revealed the growing prevalence rate of asthma from $8 \%$ to $23 \%$ between 1986 and 1995 . Also, the same study found many environmental influences associated with asthma, such as tobacco smoke and indoor pets (3). In another epidemiological study, the International Study of Asthma and Allergies in Children (ISAAC), a questionnaire was used to assess the prevalence of asthma and its principal symptoms in 16- to 18-year-old adolescents in Riyadh. This study showed that the prevalence of lifetime wheeze was $25.3 \%$, wheeze during the past 12 months was $18.5 \%$, physician-diagnosed asthma reported by $19.6 \%$, exercise-induced wheezing by $20.2 \%$ and night coughing $25.7 \%$ (4).

Asthma can be a significant burden on patients, families, and society, by increasing absenses from school, thus impairing children's education, reducing quality of life as well as recurrent emergency department visits and hospitalization (4,5). A previous study has focused on determining the impact of bronchial asthma on quality of life among the affected children and adolescents in Taif city; the result revealed that children and adolescents with poor control experience a greater effect on their life than children and adolescents with good control (6).

The determinants of asthma can be divided into two broad categories: environmental and host. Host determinants include a family history of allergies, atopy and genetic factors (7). Multiple environmental factors are also likely to play an important role in the triggering of asthma from childhood with a combination of host factors, including air pollution, indoor and outdoor allergens and exposure to tobacco smokers (8, 9). Moreover, in Najran in Southwestern Saudi Arabia, a study was conducted to assess possible environmental and dietary determinants of asthma among school-aged children. The study showed a positive association of asthma and several environmental factors such as the presence of dogs in the house, exposure to dense truck traffic on the street, utilizing wood as a cooking fuel, eating eggs and vegetables. Seafood, fruit, and dairy products, in contrast, appear as protective factors (9).

To our knowledge, no study has yet described the prevalence of asthma among children in Al-Madinah.

The aim of this study is to estimate the prevalence of bronchial asthma among children, to determine environmental and dietary risk factors associated with bronchial asthma among children and to evaluate the severity of bronchial asthma and its effect on the quality of life.

\section{Materials and Methods:-}

Parents of all study subjects gave informed written consent for inclusion before participation in the study.

2.1. Study Design and Target Population

The study is a cross-sectional study on a representative sample of Saudi male and female children at The Maternity and Children's Hospital, Al-Madina, Saudi Arabia. The inclusion criteria were: children 14 years old or younger, Saudi males and females. Exclusion criteria were: more than 14 years old, non-Saudi males and females.

2.2. Study period: From March to May 2018.

2.3. Sample Size Determination and Sampling: At 95\% confidence interval: population 1,000000, sample size 384 children.

2.4. Questionnaire Interview: A predesigned questionnaire will be filled by participant children's parents. The questionnaire is in Arabic and is a validated version. It contains only two questions about bronchial asthma, to identify respiratory symptoms in the last 12 months (such as wheezy chest, difficulty in breathing, nocturnal cough or coughing after exercise) and to identify physician-diagnosed bronchial asthma. It also requests the following information: personal data such as age, sex, and weight; environmental factors such as exposure to outdoor/indoor air pollution, family history of smoking, having cats or dogs, vigorous exercise and use of analgesics such as aspirin or paracetamol; dietary factors such as seafood, vegetable, fruit, dairy product, eggs and fast food consumption. 
Also, the severity and control of bronchial Asthma through medications and impact on activities of daily living. The last part of the questionnaire asks about the level of treatment, drugs or spacer-use; control through medication; severity of bronchial asthma by number of days absent from school, any visits to hospital, emergency room or clinic. The validity of the questionnaire was tested through the opinions of three experts, assessing for language clarity, content, relevancy, ability to understand questions and the time needed to answer. A reliability test will be conducted for the internal consistency of the items by using reliability coefficients (Cronbach's alpha $=0.8$ ) suitable for the questionnaire.

2.5. Statistical Analysis: Statistical Package for Social Sciences (SPSS) v.23 was used in this study. Descriptive statistics were used to describe the basic features of the data in the study, through frequencies and percentages and a graphical chart. Inferential statistics were used to test the relationship between variables, through a Chi-Square test for independence. This test is applied where we have two categorical variables from a single population. It is used to determine whether there is a significant association between the two variables.

2.6. Ethical considerations: Official permission was obtained from the scientific ethical committee of the college. Informed consent was obtained from all the participants after describing the aim of the study. Privacy and confidentiality of all data were ensured.

Results:-

3.1. Demographics of the sample

Table 1:- Demographic data of the sample study ( $\mathrm{N}=384)$

\begin{tabular}{|l|l|l|l|}
\hline Demographic Variables & Count & Percent (\%) \\
\hline \multirow{3}{*}{ Aender } & Male & 218 & 56.8 \\
\cline { 2 - 4 } & Female & 166 & 43.2 \\
\hline \multirow{4}{*}{$\begin{array}{l}\text { Bge } \\
\text { For }>\text { Ne years }\end{array}$} & Less than 2 years & 45 & 11.7 \\
\cline { 2 - 4 } & From 2 to less than 10 years & 261 & 68 \\
\cline { 2 - 4 } & 10 years to $\leq 14$ years & 78 & 20.3 \\
\hline \multirow{2}{*}{$\begin{array}{l}\text { Did you (parent) smoke during } \\
\text { pregnancy? }\end{array}$} & Underweight & 282 & 83.2 \\
\cline { 2 - 4 } & Normal weight & 41 & 12.1 \\
\cline { 2 - 4 } & Overweight & 5 & 1.5 \\
\cline { 2 - 4 } & Obese & 11 & 3.2 \\
\cline { 2 - 4 } & Nos & 18 & 4.7 \\
\hline
\end{tabular}

Table (1) shows that the largest percent of the total sample was male (56.8\%), while females made up $43.2 \%$ of the total sample. Regarding age, participants from 2 to less than 10 years made up $68 \%$ of the total sample, followed by $20.3 \%$ for those 10 years to $\leq 14$ years, while $11.7 \%$ of the total sample were under 2 years old. Regarding BMI, the highest percent of participants were underweight ( $83.2 \%$ of the total sample), followed by those with normal weight with $12.1 \%$ of the total sample, while $3.2 \%$ of the total sample were obese and $1.5 \%$ were overweight. In terms of smoking, a large majority of the total sample of parents (95.3\%) didn't smoke during pregnancy, while $4.7 \%$ did.

Table (2):- Type of feeding, the presence of asthma, the use of medication among the participants

\begin{tabular}{|l|l|l|l|}
\hline & $\begin{array}{l}\text { Yes } \\
\text { (NO, \%) }\end{array}$ & $\begin{array}{l}\text { No } \\
\text { (NO, \%) }\end{array}$ & $\begin{array}{l}\text { Sometimes } \\
\text { (NO, \%) }\end{array}$ \\
\hline $\begin{array}{l}\text { Did you breastfeed your baby during the first } \\
\text { three months? }\end{array}$ & $(255,66.4 \%)$ & $(129,33.6 \%)$ & \\
\hline $\begin{array}{l}\text { Did a doctor ever tell you that your child has } \\
\text { asthma? }\end{array}$ & $(185,48.2 \%)$ & $(199,51.8 \%)$ & \\
\hline $\begin{array}{l}\text { Does your child take any medication for } \\
\text { asthma? }\end{array}$ & $(83,21.6 \%)$ & $(246,64.1 \%)$ & $(55,14.3 \%)$ \\
\hline $\begin{array}{l}\text { Do you use a spacer (tube that attaches to } \\
\text { inhaler) with your child's inhaler? }\end{array}$ & $(90,23.4 \%)$ & $(254,66.1 \%)$ & $(40,10.4 \%)$ \\
\hline
\end{tabular}


From table (2), we found that the highest percent of the total sample had breastfed their child in the first three months $(66.4 \%)$, while children who had formula feeding were $33.6 \%$ of the total sample.48.2\% of the total sample reported that their child had asthma. $21.6 \%$ of the total sample took medication for asthma, with $14.3 \%$ sometimes taking medication, while $64.1 \%$ of the total sample didn't take any medication for asthma. $23.4 \%$ of the total sample use a spacer (tube that attaches to inhaler) with their child inhaler and $10.4 \%$ sometimes do, while $66.1 \%$ of the total sample didn't.

Table (3):- The environmental factors that trigger the child's symptoms

\begin{tabular}{|l|l|l|}
\hline $\begin{array}{l}\text { What are the environmental factors that trigger your child's symptoms? } \\
\text { (Check all that apply) }\end{array}$ & $\mathrm{N}$ & $\%$ \\
\hline Smoking of people around the child at home & 99 & 25.78 \\
\hline Heavy exercise & 51 & 13.28 \\
\hline Others & 50 & 13.02 \\
\hline Exposure to car exhaust fumes & 49 & 12.76 \\
\hline Dust & 49 & 12.76 \\
\hline Cold weather & 34 & 8.85 \\
\hline Using wood for warming at home & 32 & 8.33 \\
\hline Exposure to cat at home & 27 & 7.03 \\
\hline Perfumes & 20 & 5.21 \\
\hline Incense & 18 & 4.69 \\
\hline Using wood for cooking at home & 14 \\
\hline Exposure to dogs at home & 10 & 3.65 \\
\hline Using medication, e.g. aspirin or paracetamol & 9 & 2.6 \\
\hline Nothing & 135 & 2.34 \\
\hline
\end{tabular}

Table (3) shows the environmental factors that trigger the child's symptoms. The first rank was for smoking around the child at home $(25.78 \%)$, followed by heavy exercise at $(13.28 \%)$.

Table (4):- Kinds of foods that can trigger the child's symptoms

\begin{tabular}{|l|l|l|}
\hline $\begin{array}{l}\text { What kind of foods that can trigger your child's symptoms? } \\
\text { (Check all that apply) }\end{array}$ & N & $\%$ \\
\hline Egg & 46 & 11.98 \\
\hline Milk & 41 & 10.68 \\
\hline Fast Food & 19 & 4.5 \\
\hline Seafood & 15 & 3.91 \\
\hline Fruits & 14 & 3.65 \\
\hline Vegetables & 7 & 1.82 \\
\hline None of the above & 291 & 75.78 \\
\hline
\end{tabular}

Table (4) shows that $11.98 \%$ of the total sample thought that consuming egg can trigger their child's symptoms, $10.68 \%$ thought that milk can trigger their child's symptoms, $4.5 \%$ chose fast food and $3.91 \%$ chose seafood, while $3.65 \%$ chose fruits and $1.82 \%$ chose vegetables. $75.78 \%$ of the total sample chose none of the above

Table (5):- Medication for asthma and the name of inhaler or medicines taken by the children

\begin{tabular}{|l|l|l|}
\hline $\begin{array}{l}\text { If your child takes any medication for asthma, regularly or } \\
\text { sometimes, what is the name of the inhaler or medicine(s)? }\end{array}$ & $\mathrm{N}$ & $\%$ \\
\hline Ventoline Evohalar & 85 & 61.59 \\
\hline Flixotide Evoholar & 41 & 29.71 \\
\hline Histop & 5 & 3.62 \\
\hline Dramylin & 4 & 2.91 \\
\hline Mortilium & 3 & 2.17 \\
\hline & 138 & $100 \%$ \\
\hline
\end{tabular}


Table (5) shows the name of the inhaler or medicines that children take. $61.59 \%$ of the total sample who indicated that they took some medicine (138 of 384) take Ventoline Evohalar, 29.71\% take Flixotide Evoholar, 3.62\% take Histop, $2.91 \%$ take Dramylin and $2.17 \%$ take Mortilium.

Table (6):- When does your child use the inhaler?

\begin{tabular}{|l|l|l|}
\hline If yes, when do your child take it? & $\mathrm{N}$ & $\%$ \\
\hline When they have shortness of breath or coughing & 95 & $68.84 \%$ \\
\hline Every day, even when he /she feeling well & 39 & $28.26 \%$ \\
\hline Before sports & 4 & $2.90 \%$ \\
\hline & 138 & $100 \%$ \\
\hline
\end{tabular}

$68.84 \%$ of the children who take medicines take it when they experience shortness of breath or coughing, $28.26 \%$ take it every day, even when feeling well, and $2.90 \%$ take it before sports, as shown in Table (6).

Table (7):- The need to stay in hospital, go to the emergency room or to the clinic

\begin{tabular}{|l|l|l|}
\hline In the last year, has your child needed to: & $\mathrm{N}$ & $\%$ \\
\hline Stay overnight in the hospital for one day or more & 63 & 16.4 \\
\hline Gone to the emergency room & 96 & 25 \\
\hline Gone to the clinic & 31 & 8.1 \\
\hline None of the above & 194 & 50.5 \\
\hline Total & 384 & $100 \%$ \\
\hline
\end{tabular}

When participants were asked about needing to stay overnight in the hospital for one day or more for their child, $16.4 \%$ of the total sample answered that they had needed to in the past year, $25 \%$ of the total sample had needed to go to the emergency room, while $8.1 \%$ had needed to go to the clinic. However, $50.5 \%$ of the total sample had not needed any of the above.

Table (8):-Days of school missed because of asthma this year

\begin{tabular}{|l|l|l|}
\hline $\begin{array}{l}\text { How many days of school has your child missed the school year } \\
\text { because of asthma? }\end{array}$ & N \\
\hline Less than 5 days & 48 & 12.5 \\
\hline One week & 2 & 0.5 \\
\hline Two weeks & 37 & 9.6 \\
\hline One month & 15 & 3.9 \\
\hline More than month & 6 & 1.6 \\
\hline None & 276 & 71.9 \\
\hline Total & 384 & $100 \%$ \\
\hline
\end{tabular}

When participants were asked about how many days of school their child had missed this school year because of asthma, $12.5 \%$ of the total sample answered less than 5 days, followed by $9.6 \%$ who had missed two weeks, followed by $3.9 \%$ who had missed one month, followed by $1.6 \%$ who had missed more than one month; $0.5 \%$ had missed one week. $71.9 \%$ of the total sample answered none, as shown in Table (8).

Table (9):- Association between breastfeeding baby during the first three months and symptoms of bronchial asthma among children (N-384):

\begin{tabular}{|l|l|l|l|l|}
\hline $\begin{array}{l}\text { In the past } \begin{array}{l}\text { Formula feeding } \\
\text { notice in your child? }\end{array} \\
\text { Shortness of breath }(\mathrm{N}=144,38 \%)\end{array}$ & $\begin{array}{l}\text { Breastfeeding } \\
(255,66.4 \%)\end{array}$ & $\mathrm{P}$ \\
\cline { 2 - 5 } & $\mathrm{N}$ & $\%$ & $\mathrm{~N}$ & 12 \\
\hline Wheezing $(\mathrm{N}=125,33 \%)$ & 97 & 25 & 47 & 13 \\
\hline Coughing at night $(\mathrm{N}=181,47 \%)$ & 76 & 20 & 49 & 15 \\
\hline Coughing after exercise $(\mathrm{N}=60,16 \%)$ & 123 & 32 & 58 & 5 \\
\hline None of the above $(\mathrm{N}=120,31 \%)$ & 42 & 11 & 18 & $5.022 *$ \\
\hline
\end{tabular}


From Table (9), we found that the highest percent of the total sample (47\%) recorded coughing at night (by $32 \%$ of those who had used breastfeeding and $15 \%$ for formula feeding), followed by $38 \%$ recording shortness of breath ( $25 \%$ of those breastfeeding and $12 \%$ for formula feeding), followed by $33 \%$ noticing wheezing (20\% of those breastfeeding and $13 \%$ for formula feeding), followed by $16 \%$ noticing coughing after exercise (11\% of those breastfeeding and $5 \%$ for formula feeding), while $31 \%$ of the total sample choose None of the above (21\% of those breastfeeding and $10 \%$ for formula feeding).

Results of a Chi-Square test from Table (9) showed that there is a statistically significant association between breastfeeding a baby during the first three months and symptoms of bronchial asthma among children, since ChiSquare $(26.567)$ had P-value $(0.022<0.05)$. Figure 1 shows these results.

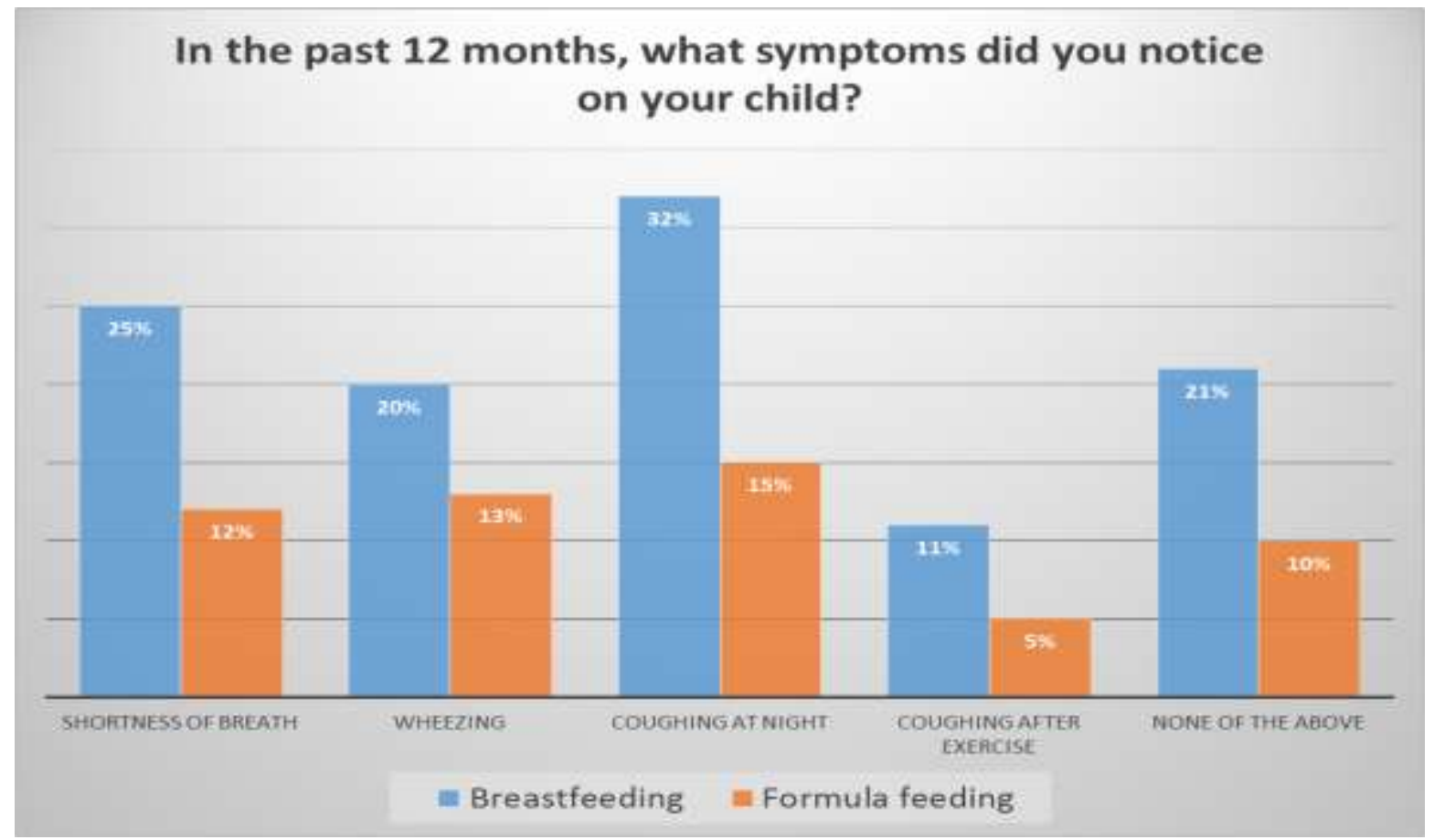

Fig (1):- Difference between breast and formula feeding as regards symptoms noticed in the child over the past 12 months.

\section{Discussion:-}

To the best of our knowledge, this is the first study conducted among children in Al-Madina, Saudi Arabia that explores the epidemiology and environmental determinants of bronchial asthma. These results confirm previous studies in Sweden (10) and France (11) which reported that bronchial asthma is more prevalent in boys than girls. Before puberty boys are more likely to have bronchial asthma, but after puberty the reverse occurs (12). This could be due to environmental factors or hormonal factors such as sex hormones, which play an important role in mechanisms of regulating airway inflammation (10). Also, there is a higher level of total immunoglobulin $\mathrm{E}(\operatorname{IgE})$ in boys than girls, which is considered a risk factor for any sensitization (10).

The current study found a negative relation between obesity and asthma symptoms in children older than 2 years. This was in contrast to the findings in a study previously conducted in the United Kingdom, which revealed a strong association between asthma and body mass index (13). Also, there is a positive significant association between maternal smoking in pregnancy and risk of bronchial asthma, which is confirmed by several studies in Southern California (14) and Finland (15).

Fetus exposure to the carcinogens in tobacco during pregnancy can lead to the forming of active compounds, with consequent effects on the maturation of the pulmonary immune system and decreased lung function (14). Environmental tobacco smoke or passive smoking was considered as one of the strongest and most widespread environmental risk factors by several studies in Germany (16) and Sweden (17); our results confirm those studies, as 
they report recurrent nocturnal coughing/wheezing, which is positively associated with passive smoking, in $28 \%$ of the total sample. Reducing this important risk factor in the community will lead to a great positive effect on asthmatic children (17).

Human milk during first three months of life remains a matter of controversy on the development of asthma, with some evidence for protective effects against asthma symptoms (18). In contrast to the previous studies conducted in Sweden (19) and in Germany (20), which found that breastfeeding for at least three months protects against wheezing in early life (18), the current study revealed that exclusive breastfeeding during the first three months increased the risk of bronchial asthma. Differently again, in a previous study in the United States, they reported that recurrent wheezing increased after the age of three years only if the mother had asthma (21).

In the present study, breastfeeding was found to be a significant predictor positively affecting the prevalence of asthma in children. Findings on the effects of breastfeeding on the development of asthma have been controversial. A previous study in New Zealand showed that breastfeeding increases risk in the development of asthma at nine years of age (22). Another research study which was carried out in Italy found that exclusive breastfeeding during the first three months or more of life is correlated with lower risk of childhood asthmatic symptoms (23). Two previous studies did not find any association between breastfeeding and asthma $(24,25)$. These variations between different studies may reflect differences in cultures, environments and perinatal diet among different demographic areas. However, the exact mechanism of the effect of breastfeeding on asthma is still unknown. Therefore, further investigation should be carried out to explain such a mechanism.

The current study revealed that less than half of the diagnosed children with bronchial asthma were taking medication or using spacers, which indicate poor compliance, for personal, socioeconomic or physical reasons. Also, in some asthmatic children, there was difficulty in using inhalers, perhaps related to low levels of education and lack of awareness among parents about the seriousness of the disease and its complications (26). Asthma symptoms increase in children during vigorous exercise because it induces bronchospasm (16). This is confirmed by the results of this study, which revealed a positive relationship between nocturnal dry cough/wheezing and doing vigorous exercise, reported by $15 \%$ of the total sample. This was in line with the finding of previous studies in Southwestern Saudi Arabia (9), Germany (16) and Sweden (17). At the same time, however, it contrasts with the results reported in Finland (27).

Exposure to air pollution caused by truck traffic or industry will trigger oxidative stress, inflammation of the airway, and consequently exacerbate asthma in children (16). In the current study, there is a positive significant relationship between nocturnal dry cough/dyspnea and car exhaust fumes, reported by $9 \%$ of the total sample, these results were found in previous studies in Southwestern Saudi Arabia (9) and Germany (16). The current study found several different irritants, including dust, perfume, and incense, which exacerbated nocturnal dry cough, dyspnea and wheezing in children. This is confirmed by multiple studies in Southwestern Saudi Arabia (9) and Germany (16).

In this current research, there was a positive significant association between egg consumption and nocturnal dry cough, reported by $12.43 \%$ of asthmatic children; this is in accord with what was reported in the previous study in Southwestern Saudi Arabia (9). Moreover, a positive association was observed between seafood and nocturnal dry cough, by $6.48 \%$ of total asthmatic children, which in contrast to the finding of the previous study in Southwestern Saudi Arabia (9). Our results revealed that there is a positive association between fast food consumption and prevalence of nocturnal dry cough/ dyspnea, noted among $10.27 \%$ of the total asthmatic children, which is in line with the findings of the previous studies conducted in Italy (28) and in Saudi Arabia (29). Fatty acids ingestion will lead to changes in immune reactions (30). Our results revealed the presence of a positive relationship between dairy intake and risk of diagnosed and severe asthma among $12.97 \%$ of the total asthmatic children; this result goes against the findings of the previous study in Southwestern Saudi Arabia (9). The current study found a positive relation between fruit such as banana and guava intake and nocturnal dry cough/ wheezing, reported by $10.27 \%$ of total asthma sufferers, which is in contrast to the finding of previous studies in Southwestern Saudi Arabia (9) and Jeddah, Saudi Arabia (29). Also, in a small group of asthmatic children in our study, we found a positive relationship between vegetable consumption and wheezing, which accords with the results reported in Southwestern Saudi Arabia (9) but goes against findings in the previous study in Italy (28).

This study showed that most of the patients inhaled short-acting beta agonist (Ventolin) as quick relief from acute asthma attacks, which was very close to the $58.8 \%$ reported by Hamam (31). We found that inhaled corticosteroid 
(Flixotide) was used as a prophylactic treatment against asthma symptoms in $29.71 \%$ of children. Inhaled corticosteroid is considered to be one of the most effective medications used to suppress inflammation, if used properly (32). Antihistamine drugs (histop) had been prescribed to $3.62 \%$ of children. This is in agreement with Grant (33), who found that an antihistamine treats allergic rhinitis as well as asthma. In that study, randomized patients reported a significant improvement in wheezing, shortness of breath, cough, and nocturnal asthma when compared with controls groups. In our study, $2.91 \%$ of patients take Dramylin, which is a first-generation H1 antagonist that inhibits histamine-induced allergic symptoms. Studies about Dramylin are limited in the literature but our study suggests it may be used to manage allergic conditions associated with asthma. About $2.17 \%$ of children managed their symptoms with Mortilium (domperidone), probably because of the relationship between gastroesophageal reflux disease and bronchial asthma, as reported in Sharma (34).

A cross-sectional study conducted by Al-Dawood (35) found that $65.2 \%$ of children in Al-Khobar city have visited a hospital emergency department and $12 \%$ needed hospital admission. On the other hand, the rate of hospital admission more than once, as measured by Lasmar, was $65.3 \%$ (36). Hamam also found that $51.4 \%$ of children had visited a family doctor once per season in the last 6 months (31). In contrast, our data indicates that the majority of asthmatic participants didn't need to visit the hospital. This may be due to differences in asthma severity and type of treatment needed to maintain good control.

Several types of research reported that bronchial asthma markedly affects the quality of life of affected children (37, 38). In recent research from Riyadh, KSA among asthmatic patient (11-19 years old), the school attendance scores were significantly worse in some moderate and severe patients, comparative to children with intermittent asthma (39). Bronchial asthma also has been considered as one of the most common causes of school absence, impairing children's education and reducing the quality of life (4). This result showed that $71.9 \%$ of children had not been absent from their schools this year. This finding could be due to the proper assessment, treatment, and management of asthmatic patients. Another reason may be the infrequent hospitalization or emergency room visits by asthmatic participants, as shown in Table 7.

\section{Conclusion:-}

Our study identifies the prevalence of bronchial asthma among children in Al-Madina, which is that $48.2 \%$ of the total sample has asthma. Also, the study demonstrated that passive smoking was the most widespread environmental risk factor that trigger asthma symptoms, reported by $25.78 \%$. Moreover, egg consumption was the most common dietary risk factors associated with asthmatic children, noted by $11.98 \%$. To evaluate the severity of bronchial asthma, our result showed that $71.9 \%$ of children had not been absent from their schools in this year, and the majority of asthmatic participants did not need to visit the hospital.

\section{Acknowledgment:-}

This study was supported by the Maternity and Children's Hospital, Al-Madina, Saudi Arabia. Ghadi Kaled Alsaadi and Haneen Hassan Almuhammadi, medical students at the college of medicine Taibah University, participated in conducting the research as data collectors.

\section{References:-}

1. To, T., Stanojevic, S., Moores, G., et al (2012): Global asthma prevalence in adults: findings from the crosssectional world health survey. BMC public health, 2012. 12: 204.

2. Al-Moamary MS, Alhaider SA, Al-Hajjaj MS, Al-Ghobain MO, Idrees MM, Zeitouni MO, et al. (2012) The Saudi initiative for asthma - 2012 update: Guidelines for the diagnosis and management of asthma in adults and children. Ann Thorac Med 2012; 7:175-204.

3. Al-Frayh, A.R., Shakoor Z, Gad El Rab, M. O., Hasnain, S. M. (2001): Increased prevalence of asthma in Saudi Arabia. Ann Allergy Asthma Immunol. 2001; 86(3):292-6.

4. Al Ghobain, M.O., Al-Hajjaj, M.S., Al Moamary, M.S. (2012) Asthma prevalence among 16-to 18-year-old adolescents in Saudi Arabia using the ISAAC questionnaire. BMC Public Health 2012; 12:239.

5. Guilbert, T. W., Garris, C., Jhingran, P., Bonafede, M., Tomaszewski, K. J., Bonus, T., Hahn, R. M. \& Schatz, M. (2011). Asthma that is not well-controlled is associated with increased healthcare utilization and decreased quality of life. J Asthma, 48(2): 126-132, ISSN 1532-4303.

6. Al Zahrani, Saad S., et al. (2014) The impact of bronchial asthma on quality of life among affected children and adolescents in Taif city, Saudi Arabia. Life Sci J 11(6): 283- 
7. Holloway, J. W., Yang, I. A., and Holgate, S. T. (2010) Genetics of allergic disease. Journal of Allergy and Clinical Immunology 125(2): S81-S94.

8. D'Amato, G., Cecchi, L., D'Amato, M., Liccardi, G. (2010) Urban air pollution and climate change as environmental risk factors of respiratory allergy: an update. J InvestigAllergolClinImmunol. 20(2): 95-102.

9. Alqahtani, Jobran, M., et al. (2016) Environmental Determinants of Bronchial Asthma among Saudi School Children in Southwestern Saudi Arabia. International journal of environmental research and public health 14(1): 22.

10. Almqvist, Catarina, et al. (2008) Impact of gender on asthma in childhood and adolescence: a GA2LEN review. Allergy 63(1): 47-57.

11. Saadeh, Danielle, et al. (2015) Prevalence and association of asthma and allergic sensitization with dietary factors in schoolchildren: data from the French six cities study. BMC public health 15(1): 993.

12. Camargo, Carlos, A., et al. (2005) Prospective study of body mass index, weight change, and risk of adult-onset asthma in women. Archives of internal medicine 159(21): 2582-2588.

13. Wickens, K., et al. (2005) Obesity and asthma in 11-12 year old New Zealand children in 1989 and 2000. Thorax 60(1): 7-12.

14. Gilliland, F. D., Yu-Fen L., and Peters, J. M. (2001) Effects of maternal smoking during pregnancy and environmental tobacco smoke on asthma and wheezing in children. American journal of respiratory and critical care medicine 163(2): 429-436.

15. Jaakkola, Jouni J.K., and Gissler, M. (2004) Maternal smoking in pregnancy, fetal development, and childhood asthma. American journal of public health 94(1): 136-140.

16. Bacharier, L. B., et al. (2008) Diagnosis and treatment of asthma in childhood: a PRACTALL consensus report. Allergy 63(1): 5-34.

17. Janson, Christer. (2004) The effect of passive smoking on respiratory health in children and adults [State of the Art]. The International Journal of Tuberculosis and Lung Disease 8(5): 510-516.

18. Greer, F. R., Sicherer, S. H., and Burks, A. W. (2008) Effects of early nutritional interventions on the development of atopic disease in infants and children: the role of maternal dietary restriction, breastfeeding, timing of introduction of complementary foods, and hydrolyzed formulas. Pediatrics 121(1): 183-191.

19. Kull, Inger, et al. (2010) Breast-feeding in relation to asthma, lung function, and sensitization in young schoolchildren. Journal of Allergy and Clinical Immunology 125(5): 1013-1019.

20. Nagel, Gabriele, et al. (2009) Effect of breastfeeding on asthma, lung function and bronchial hyperreactivity in ISAAC Phase II. European Respiratory Journal 33(5): 993-1002.

21. Wright, A. L., et al. (2001) Factors influencing the relation of infant feeding to asthma and recurrent wheeze in childhood. Thorax 56(3): 192-197.

22. Sears, Malcolm R., et al. (2002) Long-term relation between breastfeeding and development of atopy and asthma in children and young adults: a longitudinal study. The Lancet 360(9337): 901-907.

23. Bandoli, Gretchen, et al. (2015) Breastfeeding and asthmatic symptoms in the offspring of Latinas: the role of maternal nativity. Journal of immigrant and minority health 17(6): 1739-1745.

24. Halpern, Salmon R., et al. (1973) Development of childhood allergy in infants fed breast, soy, or cow milk. Journal of Allergy and Clinical Immunology 51(3): 139-151.

25. Gustafsson, D., Löwhagen, T., and Andersson, K. (1992) Risk of developing atopic disease after early feeding with cows' milk based formula. Archives of disease in childhood 67(8): 1008-1010.

26. Chapman, K. R., et al. (2000) Improving patient compliance with asthma therapy. Respiratory medicine 94(1): 2-9.

27. Kilpeläinen, Maritta, et al. (2006) Body mass index and physical activity in relation to asthma and atopic diseases in young adults. Respiratory medicine 100(9): 1518-1525.

28. Farchi, Stephen, et al. (2003) Dietary factors associated with wheezing and allergic rhinitis in children. European Respiratory Journal 22(5): 772-780.

29. Hijazi, Nariman, BahaaAbalkhail, and Anthony Seaton. (2000) Diet and childhood asthma in a society in transition: a study in urban and rural Saudi Arabia. Thorax 55(9): 775-779.

30. Ellwood, Philippa, et al. (2013) Do fast foods cause asthma, rhinoconjunctivitis and eczema? Global findings from the International Study of Asthma and Allergies in Childhood (ISAAC) Phase Three. Thorax (2013): thoraxjnl-2012.

31. Hamam, Fayez, et al. (2015) The prevalence of asthma and its related risk factors among the children in Taif area, Kingdom of Saudi Arabia. Prevalence 4(3): 179-184.

32. Hossny, Elham, et al. (2016) The use of inhaled corticosteroids in pediatric asthma: update. World Allergy Organization Journal 9(1): 26. 
33. Grant JA, Nicodemus CF, Findlay SR, et al. (1995) Cetirizine in patients with seasonal rhinitis and concomitant asthma: Prospective, randomized, placebo-controlled trial. J Allergy ClinImmunol 95:923-932.

34. Sharma, Bhavneesh, et al. (2007) Effect of omeprazole and domperidone on adult asthmatics with gastroesophageal reflux. World Journal of Gastroenterology: WJG 13(11): 1706.

35. Al-Dawood K.M. (2002) Schoolboys with bronchial asthma in Al-Khobar City, Saudi Arabia: Are they at increased risk of school absenteeism? J Asthma 39:413-20.

36. Lasmar, Laura Maria de Lima Belizario, et al. (2006) Risk factors for multiple hospital admissions among children and adolescents with asthma. JornalBrasileiro de Pneumologia 32(5): 391-399.

37. Hill, R. A., Standen, P. J., and Tattersfield, A. E. (1989) Asthma, wheezing, and school absence in primary schools. Archives of disease in childhood 64(2): 246-251.

38. Merikallio, VJ.; Mustalahti, K., Remes, ST., Valovirta, EJ. \& Kaila, M. (2005) Comparison of quality of life between asthmatic and healthy school children. Pediatr Allergy Immunol, 16(4): 332-340, ISSN 0905-6157 23.

39. Halwani, R., et al. (2016) Impact of Asthma on the Quality of Life of Adolescent Patients from Saudi Arabia. Lung Dis Treat 2: 114. doi: 10.4172/2472-1018.1000114 Page 2 of 6 Lung Dis Treat, an open access journal ISSN: 2472-1018 Volume 2• Issue 3• 1000114 Mean age (years) \pm S. Dev. Table 1: Characteristics and frequencies of the recruited adolescent asthmatic patients." Category Variables $\S$ HRQL scores by groups* P values Intermittent Mild Moderate Severe Persistent persistentpersistent Physical activities Q 1 (2016): 3. 